\title{
Expiratory Flow Limitation and Its Relation to Dyspnea and Lung Hyperinflation in Patients with Chronic Obstructive Pulmonary Disease: Analysis Using the Forced Expiratory Flow-Volume Curve and Critique
}

\author{
Billy Peng ${ }^{1,2}$, Matthew Miller ${ }^{1,2}$, Mark Slootsky ${ }^{1,2}$, Ravi Patel ${ }^{1,2}$, Ahmet Baydur ${ }^{1,2 *}$ \\ ${ }^{1}$ Division of Pulmonary, Critical Care, and Sleep Medicine, Keck School of Medicine, University of Southern California, \\ Los Angeles, CA, USA \\ ${ }^{2}$ Los Angeles County + University of Southern California Medical Center, Los Angeles, CA, USA \\ Email: ^baydur@usc.edu
}

How to cite this paper: Peng, B., Miller, M., Slootsky, M., Patel, R. and Baydur, A. (2021) Expiratory Flow Limitation and Its Relation to Dyspnea and Lung Hyperinflation in Patients with Chronic Obstructive Pulmonary Disease: Analysis Using the Forced Expiratory Flow-Volume Curve and Critique. Open Journal of Respiratory Diseases, 11, 91-104.

https://doi.org/10.4236/ojrd.2021.113009

Received: July 13, 2021

Accepted: August 21, 2021

Published: August 24, 2021

Copyright $\odot 2021$ by author(s) and Scientific Research Publishing Inc. This work is licensed under the Creative Commons Attribution International License (CC BY 4.0).

http://creativecommons.org/licenses/by/4.0/ (c) (i) Open Access

\begin{abstract}
Background: Tidal expiratory flow limitation (tEFL) is defined as absence of increase in air flow during forced expiration compared to tidal breathing and is related to dyspnea at rest and minimal exertion in patients with chronic airflow limitation (CAL). Tidal EFL has not been expressed as a continuous variable $(0 \%-100 \%)$ in previous analyses. Objective: To relate the magnitude of tEFL to spirometric values and Modified Medical Research Council (MMRC) score and Asthma Control Test (ACT). Methods: Tidal EFL was computed as percent of the tidal volume $(0 \%-100 \%)$ spanned (intersected) by the forced expiratory-volume curve. Results: Of 353 patients screened, 192 (114 M, $78 \mathrm{~F}$ ) patients (136 with COPD, 56 with asthma) had CAL. Overall characteristics: (mean \pm SD) age $59 \pm 11$ years, BMI $28 \pm 7$, FVC (\% pred) 85 \pm 20 , FEV1 (\% pred) $66 \pm 21$, FEV1/FVC $55 \% \pm 10 \%$, RV (\% pred) $147 \pm 42$. Tidal EFL in patients with tEFL was $53 \% \pm 39 \%$. Using univariate analysis, strongest correlations were between tEFL and FVC and between tEFL and RV in patients with $\mathrm{BMI}<30 \mathrm{~kg} / \mathrm{m}^{2}$. In patients with nonreversible CAL, tEFL was positively associated with increasing MMRC, negatively with spirometric measurements, and positively with RV/TLC. In asthmatics, ACT scores were higher in patients with mean BMI $\geq 28 \mathrm{~kg} / \mathrm{m}^{2}$ ( $\left.\mathrm{p}<0.00014\right)$ and RV/TLC values $>40 \%(\mathrm{p}<0.03)$. Conclusions: Dyspnea is strongly associated with tEFL and lung function, particularly in patients with nonreversible CAL. Air trapping and BMI contribute to tEFL.
\end{abstract}




\section{Keywords}

Air Trapping, Asthma, Chronic Obstructive Pulmonary Disease, Dyspnea, Forced Expiratory Flow-Volume Curve, Hyperinflation, Tidal Expiratory Flow Limitation

\section{Introduction}

Tidal expiratory flow limitation (tEFL) is defined as absence of increase in air flow during forced expiration effort compared to tidal breathing and correlates with dyspnea at rest better than it does with $\mathrm{FEV}_{1}$ [1] [2] [3]. Tidal EFL is also closely associated with dynamic hyperinflation in patients with chronic airflow limitation [3] [4] and increased ventilatory demand which potentially stresses cardiopulmonary reserves in patients with advanced airflow limitation [5]. Symptoms of chronic dyspnea vary, however, in patients with similar levels of airflow limitation as assessed by spirometry. In particular, $\mathrm{FEV}_{1}$ has been found to have a weak correlation with dyspnea [3] [4] while assessment of tEFL has been shown to associate closely with dyspnea [3] [4].

Tidal EFL was first described as part of the evaluation of forced expiratory flow-volume (FEFV) curves in the 1960's [6] [7]; subsequent research has shown this approach to be unreliable because of variability in static lung recoil and airway resistance following a deep inspiration, and time-dependent lung emptying and viscoelastic forces in the lung [1]. A simple method to detect tEFL, the negative expiratory pressure (NEP) technique, developed in the mid-1990s by Koulouris and colleagues [2], avoids certain technical challenges of the FEFV curve. However, NEP requires specialized equipment for recording (not commercially available) and requires steady quiet breathing which is sometimes not possible because of subject anxiety. The operator of the testing apparatus has to remain hidden in order to avoid cortical input that might alter the subject's breathing pattern. Meanwhile, analysis of the forced expiratory flow-volume curve as part of spirometry remains the standard by which respiratory function and impairment are assessed in community and academic settings. Assessment of the magnitude of tEFL using the FEFV would provide additional evidence for its association with dyspnea. We are not aware of any quantitative analysis of association of the FEFV-generated tEFL with commonly used indices of dyspnea in patients with nonreversible and reversible airflow limitation.

The purpose of this study was to evaluate 1) the relationship of dyspnea in patients with nonreversible airflow limitation, as assessed by the modified Medical Council Dyspnea (MMRC) scale, and in reversible airway disease as assessed by the Asthma Control test (ACT), to tEFL as assessed by the conventional FEFV curve, 2) the relation of magnitude of tEFL to spirometric values and degree of air trapping, and 3) discuss how technical limitations of the FEFV maneuver might influence the findings. We analyzed tEFL as a continuous variable encompassing 
the tidal curve from $0 \%$ to $100 \%$ rather than dividing it into discreet compartments or just indicating whether it was present or not.

\section{Patients and Methods}

Retrospective analysis was conducted on data collected at Los Angeles County + University Southern California Medical Center, a 600-bed tertiary care center. The investigation was approved by the institutional review board of the USC Health Sciences Center (HS-17-00120). Patients with chronic airflow limitation included those with nonreversible chronic obstructive pulmonary disease (emphysema and chronic bronchitis), asthma and bronchiectasis. Patients with a post-bronchodilator ratio of forced expiratory volume at one second $\left(\mathrm{FEV}_{1}\right)$ to forced vital capacity (FVC) less than 0.7 met the American Thoracic Society (ATS) definition for chronic obstructive pulmonary disease (COPD) [8]. Those with a $12 \%$ and absolute increase in $200 \mathrm{~mL}$ or greater in $\mathrm{FEV}_{1}$ or $\mathrm{FVC}$ following bronchodilator were classified as having asthma or reversible airway disease. Patients with bronchiectasis (confirmed by characteristic imaging features) without response to bronchodilator were classified under the nonreversible category; if they exhibited an appropriate response they were included in the reversible airway category. Patients with non-obstructive or infiltrative respiratory diseases, chest wall and neuromuscular disorders, left ventricular heart failure, and those unable to perform lung function testing according to ATS guidelines were excluded from analysis.

Pulmonary function testing was performed in adults (age $>18$ years) between June 2011 and January 2019. Testing consisted of spirometry, lung volumes by body plethysmography, and single-breath diffusion capacity $\left(\mathrm{D}_{\mathrm{L}} \mathrm{CO}\right)$ measured in seated position according to ATS guidelines [8]. Predicted values for spirometric indices, lung volumes and single-breath carbon monoxide diffusion capacity were from Crapo and Morris [9] [10]. Dyspnea in patients with nonreversible airflow limitation was graded according to the modified Medical Research Council MMRC scale [11]. Severity of COPD was graded based on GOLD 2017 staging [12]. Symptoms in patients with asthma were graded using the ACT score [13].

\subsection{Tidal Expiratory Flow Limitation}

Patients were instructed to breathe quietly for 5 minutes or until the tidal volume remained steady (not more than $10 \%$ variation). After performing a maximal inspiration to total lung capacity followed by an immediate expiration, spirometric maneuvers were performed as per ATS guidelines [14]. Only FEFV curves with sharp peak flows were accepted for analysis. The immediately preceding tidal flow-volume curve and the corresponding forced expiratory flowvolume curve were overlaid and the portion of the flow-volume loop where there was no appreciable increase in expiratory flow was considered as flow-limited (Figure 1). Tidal EFL was computed as percent of the tidal volume $(0 \%-100 \%)$ spanned (intersected) by the forced expiratory-volume curve. (ref. [15], Figure 1). 


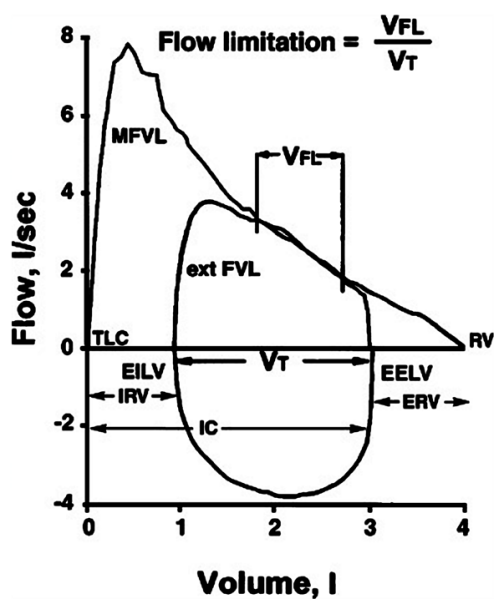

Figure 1. Intersection of the maximal forced expiratory flow-volume curve (MFVL) with the tidal volume (VT) curve. tEFL (\%) is computed as (VFL/VT) ${ }^{\star} 100$. EILV, end-inspiratory lung volume; EELV, end-expiratory lung volume; ERV, expiratory reserve volume; IRV, inspiratory reserve volume; IC, inspiratory capacity; VFL, flow-limited volume; RV, residual volume; TLC, total lung capacity. Diagram from ref. [15].

\subsection{Statistical Analysis}

Continuous variables were expressed as means and SD or medians (range), depending on normality of distribution. Spearman correlations were used to assess associations between lung function, MMRC and ACT score [16]. Differences amongst physiologic variables based on MMRC and ACT scores were assessed using analysis of variance (ANOVA) controlled for age, gender and BMI with Bonferroni correction. Separate correlation analyses were conducted for patients with BMI $\geq 30 \mathrm{mg} / \mathrm{kg}^{2}$ and those with BMI $<30 \mathrm{~kg} / \mathrm{m}^{2}$. A p $<0.05$ was taken as indicating significant differences amongst cohorts.

\section{Results}

Data for 353 patients were screened, of which 192 fulfilled criteria for analysis; $59 \%$ were male. For the entire cohort, overall mean \pm SD age and BMI was $59 \pm$ 11 years and $28 \pm 7 \mathrm{~kg} / \mathrm{m}^{2}$, respectively. Seventy patients were current, 68 were former, and 54 were never smokers. Mean $( \pm \mathrm{SD}) \mathrm{FEV}_{1}, \mathrm{FVC}, \mathrm{FEV}_{1} / \mathrm{FVC}, \mathrm{RV}$, slow VC, and RV/TLC, was $66 \% \pm 21 \%$ predicted, $85 \% \pm 20 \%$ predicted, $55 \% \pm$ $10 \%, 147 \% \pm 42 \%$ predicted, $87 \% \pm 20 \%$ predicted, and $48 \% \pm 11 \%$, respectively.

\subsection{Relation of MMRC to BMI, tEFL, Lung Function in Patients with Nonreversible Chronic Airflow Limitation}

Of the 192 patients, 136 were diagnosed with nonreversible chronic airflow limitation and 56 with asthma (airflow limitation with reversibility). BMI progressively increased with MMRC (Table 1); mean BMI was highest in the group exhibiting MMRC $4\left(30 \mathrm{~kg} / \mathrm{m}^{2}, \mathrm{p}<0.0001\right)$. As can be seen in Table 1, a progressive increase in the number of patients with each MMRC score is noted in just the GOLD D patients. By contrast, no patients in GOLD A had MMRC scores of 3 or 4 . 
Table 1. Anthropometric and physiologic characteristics of 136 patients with nonreversible chronic airflow limitation.

\begin{tabular}{|c|c|c|c|c|c|c|}
\hline & MMRC 0 & MMRC 1 & MMRC 2 & MMRC 3 & MMRC 4 & p-value \\
\hline $\mathrm{N}($ total $=136)$ & 11 & 12 & 16 & 44 & 53 & \\
\hline Age & $61 \pm 11$ & $65 \pm 10$ & $61 \pm 6$ & $63 \pm 10$ & $60 \pm 19$ & 0.79 \\
\hline Sex, M (\%) & 55 & 75 & 56 & 73 & 62 & 0.40 \\
\hline BMI $\left(\mathrm{kg} / \mathrm{m}^{2}\right)$ & $24 \pm 5$ & $23 \pm 3$ & $29 \pm 5$ & $26 \pm 6$ & $30 \pm 9$ & $5.7 \mathrm{E}-07$ \\
\hline GOLD A (n, \%) & $5(45.5)$ & $3(25)$ & $2(12.5)$ & 0 & 0 & \\
\hline GOLD B $(\mathrm{n}, \%)$ & $5(45.5)$ & $8(66.7)$ & $11(68.5)$ & $17(38.6)$ & $2(3.8)$ & \\
\hline $\operatorname{GOLD~C~}(\mathrm{n}, \%)$ & $1(9)$ & 0 & $2(12.5)$ & $17(38.6)$ & $8(15.1)$ & \\
\hline GOLD D (n, \%) & 0 & $1(8.3)$ & $1(6.5)$ & $10(22.7)$ & $43(81.1)$ & \\
\hline tEFL (\%) & $0(0-65)$ & $43.0(0-76.8)$ & $81.1(62.1-100)$ & $56(0-81)$ & $83(56-100)$ & 0.02 \\
\hline FEV1 (\% pred) & $82 \pm 21$ & $72 \pm 16$ & $56 \pm 16$ & $64 \pm 20$ & $52 \pm 20$ & $1.9 \mathrm{E}-13$ \\
\hline FVC (\% pred) & $103 \pm 18$ & $91 \pm 15$ & $76 \pm 16$ & $83 \pm 17$ & $73 \pm 22$ & $3.0 \mathrm{E}-08$ \\
\hline FEV1/FVC (\%) & $57 \pm 9$ & $56 \pm 9$ & $53 \pm 10$ & $54 \pm 10$ & $51 \pm 11$ & $1.9 \mathrm{E}-06$ \\
\hline TLC (\% pred) & $115 \pm 14$ & $112 \pm 16$ & $107 \pm 15$ & $112 \pm 19$ & $105 \pm 19$ & 0.37 \\
\hline FRC (\% pred) & $122 \pm 23$ & $124 \pm 25$ & $119 \pm 30$ & $128 \pm 27$ & $128 \pm 32$ & 0.52 \\
\hline Slow VC (\% pred) & $104 \pm 17$ & $95 \pm 16$ & $80 \pm 13$ & $85 \pm 18$ & $76 \pm 19$ & $5.0 \mathrm{E}-07$ \\
\hline RV (\% pred) & $129 \pm 40$ & $136 \pm 34$ & $149 \pm 43$ & $150 \pm 46$ & $155 \pm 45$ & 0.0052 \\
\hline FRC/TLC (\%) & $61 \pm 9$ & $64 \pm 7$ & $62 \pm 9$ & $65 \pm 8$ & $66 \pm 9$ & 0.54 \\
\hline RV/TLC (\%) & $41 \pm 11$ & $45 \pm 9$ & $50 \pm 9$ & $49 \pm 10$ & $53 \pm 10$ & $3.8 \mathrm{E}-06$ \\
\hline IC (\% pred) & $103 \pm 19$ & $91 \pm 19$ & $90 \pm 19$ & $88 \pm 21$ & $81 \pm 23$ & 0.18 \\
\hline IC/TLC (\%) & $41 \pm 10$ & $36 \pm 7$ & $38 \pm 9$ & $35 \pm 8$ & $35 \pm 9$ & 0.54 \\
\hline DLCO (\% pred) & $92 \pm 19$ & $84 \pm 13$ & $77(72-101)$ & $76 \pm 21$ & $60 \pm 24$ & 0.0017 \\
\hline
\end{tabular}

Values are means $( \pm S D)$ or medians (range). BMI, body mass index; tEFL, tidal expiratory flow limitation. FEV1, forced expiratory volume in one second; FVC, forced vital capacity; TLC, total lung capacity; FRC, functional residual capacity; slow VC, slow vital capacity; RV, residual volume; IC, inspiratory capacity; DLCO, single breath carbon monoxide diffusion capacity.

Tidal EFL was present in 113 (83\%) patients with nonreversible airflow limitation and 36 (64\%) with asthma. Median values for tEFL in nonreversible patients increased rapidly from MMRC 0 to MMRC 2, dipped slightly at MMRC 3, and reached a maximal value (mean $83 \%)$ at MMRC $4(\mathrm{p}=0.02$, Table 1$) . \mathrm{FEV}_{1}$, $\mathrm{FVC}, \mathrm{FEV}_{1} / \mathrm{FVC}$ and slow VC decreased progressively (all significant differences at $\mathrm{p}<0.001$ ) while RV/TLC increased steadily up to MMRC 3 , then more slowly, reaching a peak at MMRC $5(\mathrm{p}<0.001)$. There were insignificant decreases in IC and IC/TLC as MMRC increased, while no significant differences in FRC and TLC amongst MMRC scores were noted. Finally, DLCO exhibited a decline of $35 \%$ with MMRC progression from 0 to 4 ( $\mathrm{p}=0.0017)$.

Multivariate regression analysis between lung function values, anthropomorphic data, and MMRC score showed that the single most closely associated variable with tEFL was $\mathrm{FEV}_{1}\left(\mathrm{r}^{2}=0.33, \mathrm{p}=1.95 \mathrm{E}-13\right.$, followed by FVC $\left(\mathrm{r}^{2}=0.21, \mathrm{p}\right.$ $=2.97 \mathrm{E}-08)$ and RV/TLC $\left(r^{2}=0.15, p=3.84 \mathrm{E}-06\right)$. 
Figures 2-4 show the significant correlations between tEFL and $\mathrm{FEV}_{1}, \mathrm{FVC}$ and $\mathrm{FEV}_{1} / \mathrm{FVC}$ (all associations at $\mathrm{p}<0.0001$ ). Figure 5 and Figure 6 also show close associations between tEFL and RV and RV/TLC although the associations were 2 to 7 orders of magnitude less than for $\mathrm{FEV}_{1}$ and FVC.

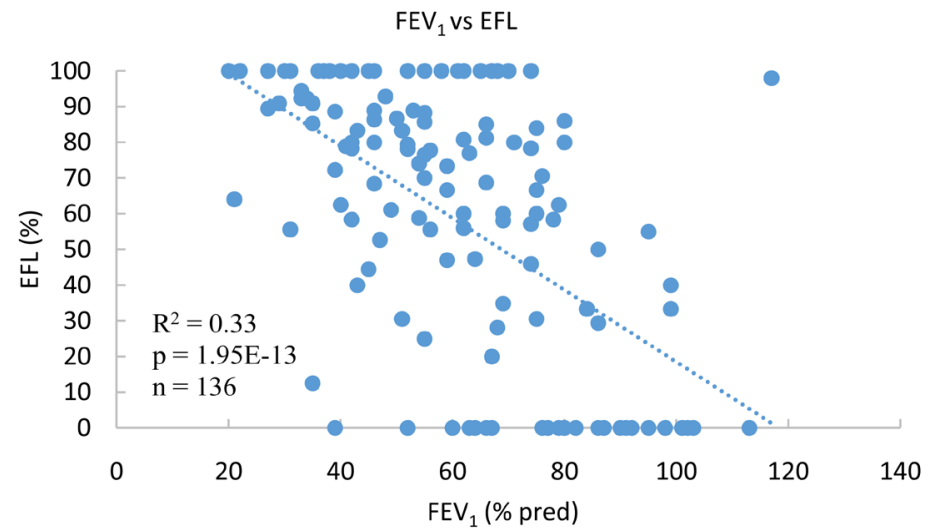

Figure 2. Relation between tidal expiratory flow limitation and $\mathrm{FEV}_{1}$ in 136 patients with nonreversible chronic airflow limitation.

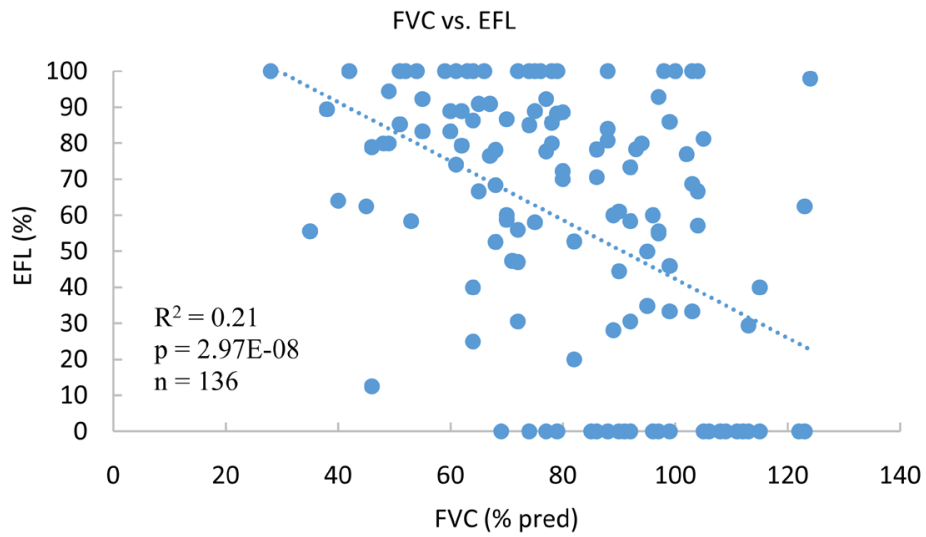

Figure 3. Relation between tidal expiratory flow limitation and FVC in 136 patients with nonreversible chronic airflow limitation.

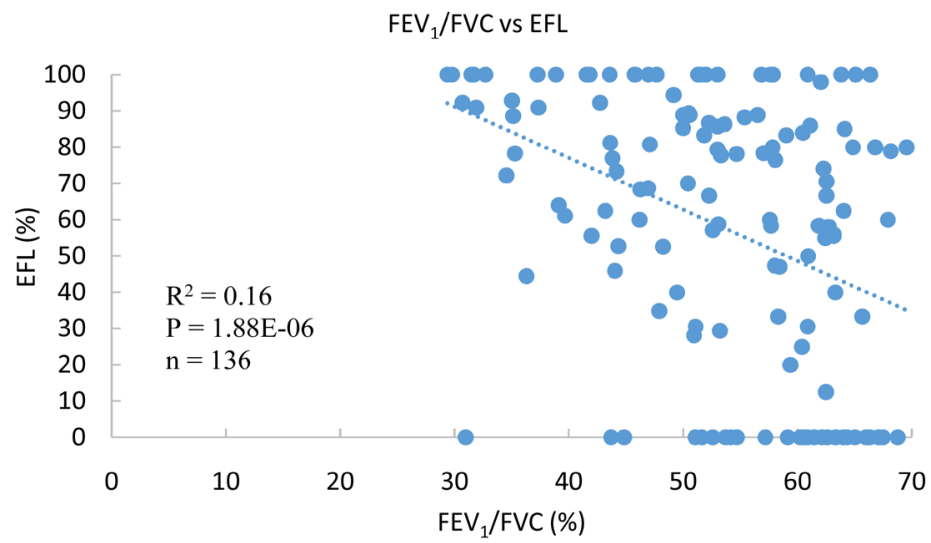

Figure 4. Relation between tidal expiratory flow limitation and $\mathrm{FEV}_{1} / \mathrm{FVC}$ in 136 patients with nonreversible chronic airflow limitation. 


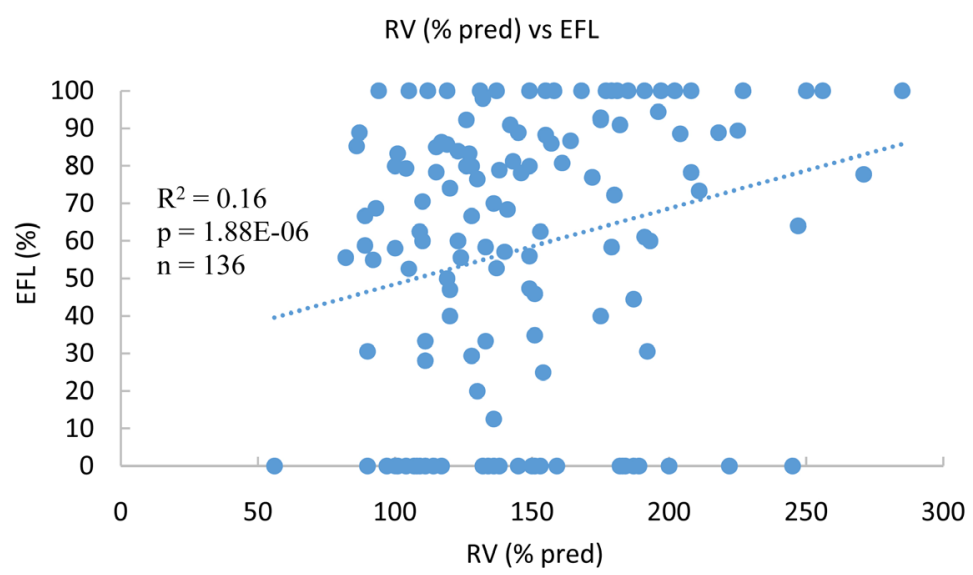

Figure 5. Relation between tidal expiratory flow limitation and RV in 136 patients with nonreversible chronic airflow limitation.

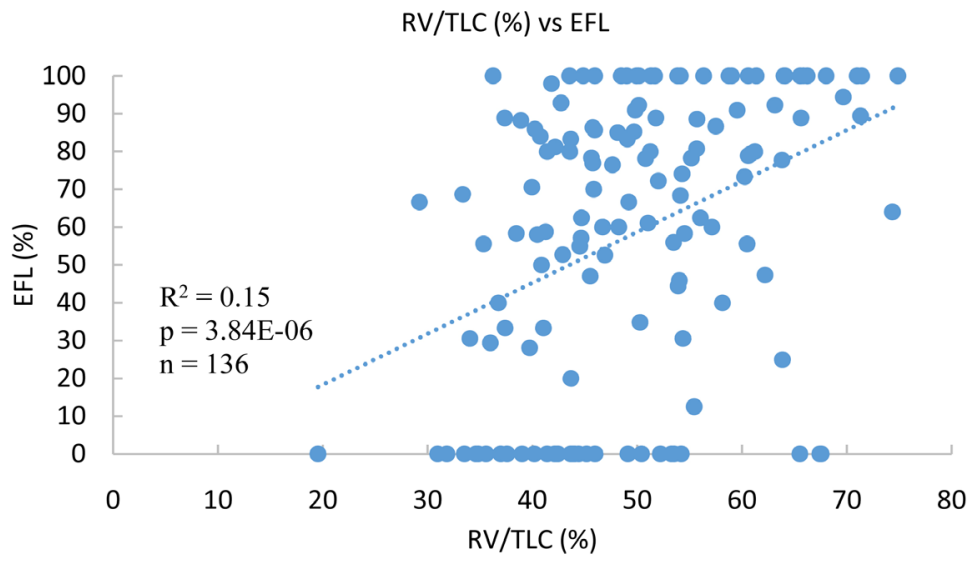

Figure 6. Relation between tidal expiratory flow limitation and RV/TLC in 136 patients with nonreversible chronic airflow limitation.

\subsection{Relation of ACT Score to BMI, Lung Function and tEFL in Asthma Patients}

Table 2 shows the same variables listed according to ACT score in 56 patients with asthma; ACT scores were subdivided into segments of 5 . Only 2 patients reported no or minimal symptoms with exertion. Amongst lung function variables, only the RV/TLC exhibited significant differences amongst cohorts $(\mathrm{p}<$ 0.03 , Figure 7). Associations between tEFL and spirometric values were not statistically significant. ACT scores were higher in patients with mean $\mathrm{BMI} \geq 28$ $\mathrm{kg} / \mathrm{m}^{2}(\mathrm{p}<0.00014)$ and RV/TLC values $>40 \%(\mathrm{p}<0.03)$. Despite the increase in air trapping, IC and IC/TLC did not change significantly over the range of ACT scores.

\section{Discussion}

The main findings in this study are that: 1) in patients with chronic nonreversible airflow limitation, tEFL was associated most closely with $\mathrm{FEV}_{1}, \mathrm{FEV}_{1} / \mathrm{FVC}$, FVC, slow VC, RV and RV/TLC, 2) in these patients, tEFL increased as MMRC 
RV/TLC vs EFL

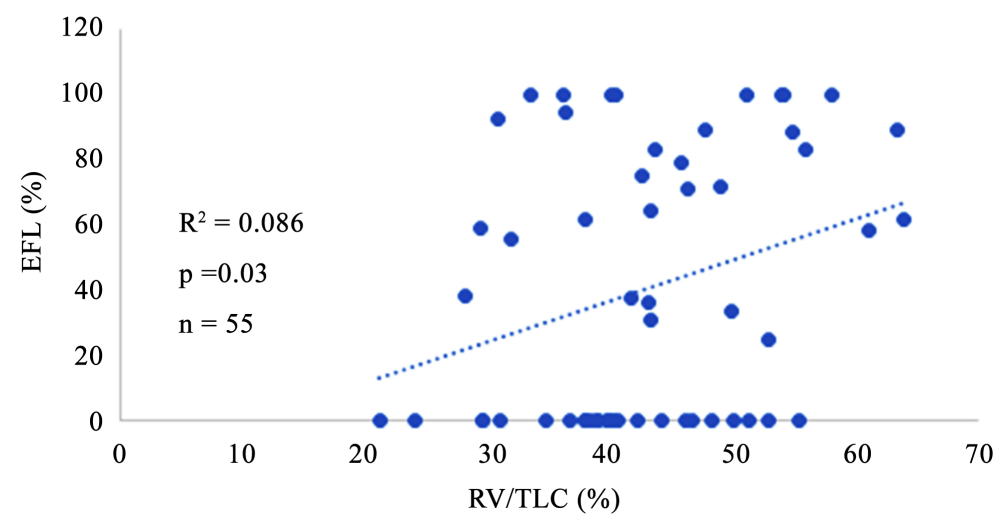

Figure 7. Relation between tidal expiratory flow limitation and RV/TLC in 55 patients with asthma.

Table 2. Anthropometric and physiologic characteristics of 56 patients with asthma.

\begin{tabular}{|c|c|c|c|c|c|c|}
\hline ACT score & $0-5$ & $6-10$ & $11-15$ & $16-20$ & $21-25$ & p-value \\
\hline $\mathrm{N}($ total $=56)$ & 2 & 19 & 10 & 10 & 15 & \\
\hline Age (yr) & $49 \pm 2$ & $49 \pm 14$ & $58 \pm 10$ & $58 \pm 12$ & $54 \pm 8$ & 0.11 \\
\hline Sex, M (\%) & 50 & 47 & 20 & 60 & 47 & 0.99 \\
\hline BMI $\left(\mathrm{kg} / \mathrm{m}^{2}\right)$ & $25 \pm 0.6$ & $28 \pm 6$ & $29 \pm 5$ & $28 \pm 6$ & $29 \pm 7$ & 0.00014 \\
\hline tEFL (\%) & $50 \pm 50$ & $38(0-92.3)$ & $49.5(0-84.8)$ & $28(0-82)$ & $25(0-71)$ & 0.23 \\
\hline FEV1 (\% pred) & $73 \pm 9$ & $75 \pm 16$ & $76 \pm 11$ & $85 \pm 21$ & $77 \pm 13$ & 0.26 \\
\hline FVC (\% pred) & $84 \pm 15$ & $95 \pm 17$ & $98 \pm 15$ & $103 \pm 18$ & $96 \pm 14$ & 0.16 \\
\hline FEV1/FVC (\%) & $66 \pm 4$ & $60 \pm 8$ & $57 \pm 6$ & $60 \pm 8$ & $60 \pm 4$ & 0.79 \\
\hline TLC (\% pred) & $91 \pm 16$ & $113 \pm 12$ & $116 \pm 19$ & $113 \pm 9$ & $115 \pm 13$ & 0.46 \\
\hline FRC (\% pred) & $93 \pm 21$ & $121 \pm 24$ & $128 \pm 27$ & $123 \pm 17$ & $125 \pm 27$ & 0.55 \\
\hline Slow VC (\% pred) & $87 \pm 13$ & $94 \pm 17$ & $95 \pm 14$ & $102 \pm 22$ & $96 \pm 13$ & 0.28 \\
\hline RV (\% pred) & $92 \pm 14$ & $147 \pm 36$ & $151 \pm 40$ & $133 \pm 34$ & $148 \pm 34$ & 0.10 \\
\hline FRC/TLC (\%) & $55 \pm 3$ & $58 \pm 11$ & $60 \pm 8$ & $61 \pm 9$ & $57 \pm 6$ & 0.22 \\
\hline RV/TLC (\%) & $34 \pm 3$ & $43 \pm 12$ & $47 \pm 6$ & $41 \pm 10$ & $43 \pm 7$ & 0.03 \\
\hline IC (\% pred) & $85 \pm 6$ & $105 \pm 26$ & $103 \pm 23$ & $101 \pm 27$ & $108 \pm 19$ & 0.082 \\
\hline IC/TLC (\%) & $45 \pm 3$ & $43 \pm 11$ & $40 \pm 8$ & $39 \pm 9$ & $43 \pm 6$ & 0.22 \\
\hline DLCO (\% pred) & 103 & $103 \pm 21$ & $92 \pm 17$ & $101 \pm 18$ & $99 \pm 23$ & 0.10 \\
\hline
\end{tabular}

Values represented same as in Table 1.

increased, 3) in patients with asthma, the ACT score was most closely associated with air trapping and tEFL, but not other lung functions, and 4) in both groups, BMI was associated with increase in perception of dyspnea and/or functional limitation.

In patients with nonreversible flow limitation, the degree of tEFL was negatively related to spirometric values, findings similar to other studies of COPD [2] 
[3] [4] [17], bronchiectasis [2] [4] and cystic fibrosis [18]; all of which employed the NEP technique. Similarly, we found that hyperinflation, as reflected by increases in RV and RV/TLC, was positively related to tEFL. We did not find an association between IC (and IC/TLC) and tEFL, in part because of the opposing effects of obesity which increased with MMRC in this group. In the studies of Koulouris et al. [4] and Holland et al. [18] IC was significantly reduced in the presence of tEFL; in contrast to our study, however, BMI did not differ amongst their seated non-tEFL and tEFL groups. Furthermore, hyperinflation is not just dependent on presence of tEFL [19]. Other contributing factors include loss of elastic recoil [20] [21], narrowing of upper and lower airways [22] [23], small airway closure [24] and post-inspiratory diaphragmatic braking activity [25].

\subsection{Critique of Use of the Forced Expiratory Flow-Volume Curve}

One of the main criticisms of using the FEFV in the determination of tEFL has been variability in lung volume history dependent on preceding deep inspirations and time-dependent lung emptying and viscoelastic forces in the lung [1]. We attempted to maintain consistent the viscoelastic properties during respiratory by asking subjects to take in the deepest breath they could prior to rapid expiration. Lung deflation occurs faster following rapid inflation as the elastic energy stored in thoracic structures is greater with rapid rather than with slow inspiration. This phenomenon was first described by Mortola et al. [26] who found that holding the breath after a maximal inspiration resulted in slower passive lung deflation. Eisaa et al. [27] and Guerin et al. [28] confirmed this finding in subsequent studies and explained it by noting that the elastic recoil pressures of the lung and chest wall gradually decrease as a result stress relaxation.

In asthmatics, deep breathing is an effective means of reversing bronchoconstriction [29] [30]. In an in vitro model of human airways, Lavoie et al. [31] found that reversal of bronchoconstriction depends on the degree of tidal expansion and is inversely related to the severity of bronchoconstriction. In our asthmatic patients, we attempted to maintain consistent bronchial tone and reactivity with maximal inspiration just prior to spirometric measurements; nevertheless these maneuvers did not prevent the heterogeneous distribution of lung function over the range of ACT scores in contrast to the distribution of lung function in COPD patients over the range of MMRC, suggesting that volume history and viscoelastic properties have different effects in asthmatics as opposed to emphysema and bronchiectasis which are characterized by parenchymal destruction.

Another criticism of using the FEFV curve has been the potential imprecision of superimposing the tidal flow-volume curve within the FEFV, because such alignment is made considering TLC as a fixed reference point [1] [2] [3]. We made no such assumption realizing that lung volumes may change slightly depending on volume and time history and viscoelastic properties. To ensure that the tidal curve was consistently related to the FEFV, equipment was checked for 
leaks before testing began and subjects were monitored for maintaining a tight mouth seal and nose clip during respiratory maneuvers. In short, we recognized the finding of tEFL to be influenced by the very factors known to affect the "concept of expiratory flow limitation" [32].

Tidal EFL was absent in only 23 (17\%) patients with nonreversible airflow limitation, and absent in 20 (36\%) with asthma. The prevalence of tEFL in nonreversible FL patients was higher than others who used the NEP technique (36\% 59\% in stable COPD patients) [2] [17] [18]. Similarly, while tEFL was less frequent in our asthmatic patients than in patients with nonreversible airflow limitation, it was more prevalent than in another study of asthma that employed the NEP technique. Boczkowski et al. [33] reported that 6 of 13 (46\%) asthmatic patients not exhibiting tEFL with the NEP technique would have been considered as having EFL by the FEFV method (ref. [33], Table 5). By contrast Filippelli et al. [34], using partial FEFV curves, found that half of their asthmatic patients exhibited tEFL, closer to our patients' prevalence of tEFL (64\%). Again, differences can be attributed to volume and time history and time-constant inequalities within the lung [33] [35].

\subsection{Relation of Symptoms to Lung Function and tEFL}

One hundred twenty five (92\%) of patients with nonreversible airflow limitation exhibited MMRC values of I or greater, with 98 patients (72\%) exhibiting a mean tEFL of 70\%. RV/TLC increased with higher MMRC scores in patients with nonreversible airflow limitation. This finding was also present in asthmatics although increases in RV and RV/TLC were not as consistent as their ACT score increased. The more progressive increase in lung volume in nonreversible COPD patients can again be explained in part by the loss of elastic recoil in these patients in contrast to the variable effects of tidal stretching on airway caliber in asthma. Furthermore, variability in airway caliber in asthmatic patients (in part related to airway remodeling) would result in fluctuating degrees of air trapping and dyspnea. Even though RV/TLC was significantly different amongst ACT cohorts, Table 1 shows that the ratio varied amongst cohorts, and only in ACT 0 - 5 was RV/TLC was lowest at 34\% (only 2 patients in this subcohort). Taking deep breaths just prior to performing spirometry was an attempt to make more consistent the lung history, but this maneuver is likely to have a more predictable effect in patients with COPD than in asthma.

\subsection{Effects of Obesity}

In general, as gas trapping increases, IC is expected to decrease with increasing tEFL. We did not find this to be the case, most likely because of the counteracting effect of obesity displacing the diaphragm more cephalad, thereby reducing the end-expiratory lung volume from its hyperinflated state. Use of the FEFV curve avoids a potential error associated with the negative expiratory pressure technique in obese patients: upper airway collapse and a false comparison with 
the immediately previous control spontaneous tidal expiration [36] [37]. As an alternative method, Ninane and colleagues [38] described the use of manual compression of the abdominal wall to demonstrate flow limitation during spontaneous breathing in different body positions in healthy subjects and patients with COPD. Despite the inherent caveats of the forced expiratory flow-volume curve, we nevertheless found that dyspnea worsened as air trapping increased, particularly in individuals with nonreversible airflow limitation.

There were limitations to our study. By employing spirometry instead of the body box to measure flow and volume, compression artifacts likely resulted in underestimation of the true maximal airflow and therefore an increase in the prevalence of tEFL [39]. This error would be magnified with increase in RV and airflow resistance. Therefore in patients with chronic airflow limitation undergoing spirometry, the error in measured expiratory flow at (for example) $50 \%$ VC could amount to as much as $50 \%$, depending on the degree of air trapping (ref. [39], Figure 4). This would have contributed to the overestimation of tEFL in our patients. Plethysmography, however, has its own limitations. Gas compression is reduced at lower lung volumes in airflow limitation. Furthermore, with severe airway obstruction, FRC and RV can be overestimated because of a lag in transmission of alveolar pressure to the mouth [40] [41] and compliance of the upper airway [42] during panting. Finally, obesity causes a reduction in expiratory reserve volume and a shift of the tidal curve towards RV, resulting in a reduction of this error by promoting tEFL.

\section{Conclusion}

Dyspnea is closely associated with tEFL, spirometric values and hyperinflation, particularly in patients with nonreversible airflow limitation. In patients with asthma, tEFL does not change significantly as ACT score increases, likely because of opposing effects of obesity and variability in airway remodeling. Air trapping and a BMI of $<30 \mathrm{~kg} / \mathrm{m}^{2}$ are strongly associated with expiratory flow limitation in patients with both reversible and chronic airflow limitation. Tidal EFL is of higher prevalence using the FEFV curve than historical values of tEFL using the negative expiratory pressure technique mainly because of volume and time history and volume inequalities within the lung. Nevertheless, while the magnitude and frequency of tEFL are greater with FEFV, relationships between tEFL, symptoms and lung function are similar to those obtained by the negative expiratory pressure technique.

\section{Acknowledgements}

The authors thank the pulmonary function technologists for performing the lung function studies.

\section{Conflicts of Interest}

The authors have no conflicts to declare. 


\section{References}

[1] Tantucci, C. (2013) Expiratory Flow Limitation: Definition, Mechanisms, Methods, and Significance. Pulmonary Medicine, 2013, Article ID: 749860. https://doi.org/10.1155/2013/749860

[2] Koulouris, N.G., Valta, P., Lavoie, A., et al. (1995) A Simple Method to Detect Expiratory Flow Limitation during Spontaneous Breathing. European Respiratory Journal, 8, 306-313. https://doi.org/10.1183/09031936.95.08020306

[3] Eltayara, L., Becklake, M.R., Volta, C.A., et al. (1996) Relationship between Chronic Dyspnea and Expiratory Flow Limitation in Patients with Chronic Obstructive Pulmonary Disease. American Journal of Respiratory and Critical Care Medicine, 154, 1726-1734. https://doi.org/10.1164/ajrccm.154.6.8970362

[4] Koulouris, N.G., Retsou, S., Kosmas, E., et al. (2003) Tidal Expiratory Flow Limitation, Dyspnoea and Exercise Capacity in Patients with Bilateral Bronchiectasis. $E u-$ ropean Respiratory Journal, 21, 743-748. https://doi.org/10.1183/09031936.03.00301103

[5] O’Donnell, D.E. and Laveneziana, P. (2006) The Clinical Importance of Dynamic Lung Hyperinflation in COPD. COPD: Journal of Chronic Obstructive Pulmonary Disease, 3, 219-232. https://doi.org/10.1080/15412550600977478

[6] Pride, N.B. and Milic-Emili, J. (1995) Lung Mechanics. In: Calverley, P. and Pride, N.B., Eds., Chronic Obstructive Lung Disease, Chapman Hall, London, 135-160. https://doi.org/10.1007/978-1-4899-4525-9 7

[7] Fry, D.L. and Hyatt, R.E. (1960) Pulmonary Mechanics. A Unified Analysis of the Relationship between Pressure, Volume and Gas Flow in the Lungs of Normal and Diseased Human Subjects. The American Journal of Medicine, 29, 672-689. https://doi.org/10.1016/0002-9343(60)90100-5

[8] Pellegrino, R., Viegi, G., Brusasco, V., et al. (2005) Interpretative Strategies for Lung Function Tests. European Respiratory Journal, 26, 948-968.

https://doi.org/10.1183/09031936.05.00035205

[9] Crapo, R.O., Morris, A.H., Clayton, P.D., et al. (1982) Lung Volumes in Healthy Nonsmoking Adults. Bulletin Européen de Physiopathologie Respiratoire, 18, 419425.

[10] Crapo, R.O. and Morris, A.H. (1981) Standardized Single Breath Normal Values for Carbon Monoxide Diffusing Capacity. The American Review of Respiratory Disease, 123, 185.

[11] Fletcher, C.M., Elmes, P.C., Fairbairn, M.B., et al. (1959) The Significance of Respiratory Symptoms and the Diagnosis of Chronic Bronchitis in a Working Population. British Medical Journal, 2, 257. https://doi.org/10.1136/bmj.2.5147.257

[12] Global Initiative for Chronic Obstructive Lung Disease (2018) Global Strategy for the Diagnosis, Management, and Prevention of Chronic Obstructive Pulmonary Disease. Report. Goldcopd.org. https://goldcopd.org/wp-content/uploads/2017/11/GOLD-2018-v6.0-FINAL-revise d-20-Nov WMS.pdf

[13] Nathan, R.A., Sorkness, C.A., Kosinski, M., et al. (2004) Development of the Asthma Control Test: A Survey for Assessing Asthma Control. The Journal of Allergy and Clinical Immunology, 113, 59-65. https://doi.org/10.1016/j.jaci.2003.09.008

[14] Graham, B.L., Steenbruggen, I., Miller, M.R., et al. (2019) Standardization of Spirometry 2019 Update. An Official American Thoracic Society and European Respiratory Society Technical Statement. American Journal of Respiratory and Critical 
Care Medicine, 200, e70-e88. https://doi.org/10.1164/rccm.201908-1590ST

[15] Johnson, B. and Weisman, I. (1999) Emerging Concepts in the Evaluation of Ventilatory Limitation during Exercise: The Exercise Tidal Flow-Volume Loop. Chest, 116, 488-503. https://doi.org/10.1378/chest.116.2.488

[16] Dixon, W.J. and Massey Jr., F.J. (1983) Introduction to Statistical Analysis. 4th Edition, McGraw-Hill, New York, 385-414.

[17] Diaz, O., Villafranca, C., Ghezzo, H., et al. (2000) Role of Inspiratory Capacity on Exercise Tolerance in COPD Patients with and without Tidal Expiratory Flow Limitation at Rest. European Respiratory Journal, 16, 269-275. https://doi.org/10.1034/j.1399-3003.2000.16b14.x

[18] Holland, A.E., Denehy, L. and Wilson, J.W. (2006) Does Expiratory Flow Limitation Predict Chronic Dyspnoea in Adults with Cystic Fibrosis? European Respiratory Journal, 28, 96-101. https://doi.org/10.1183/09031936.06.00122105

[19] Martin, J.G. (1993) Respiratory Mechanics in Asthma. The European Respiratory Review, 14, 444-447.

[20] Gold, W.M., Kaufman, M.S. and Nadel, J.A. (1967) Elastic Recoil of the Lungs in Chronic Asthmatic Patients before and after Therapy. Journal of Applied Physiology, 23, 433-438. https://doi.org/10.1152/jappl.1967.23.4.433

[21] Peress, L., Sybrecht, G. and Macklem, P.T. (1976) The Mechanism of the Increase in Total Lung Capacity during Acute Asthma. The American Journal of Medicine, 61, 165-168. https://doi.org/10.1016/0002-9343(76)90165-0

[22] Higgenbottam, T. (1980) Narrowing of the Glottis Opening in Humans Associated with Experimentally Induced Bronchoconstriction. Journal of Applied Physiology, 49, 403-407. https://doi.org/10.1152/jappl.1980.49.3.403

[23] Collette, P.W., Brancatisano, T. and Engel, L.A. (1986) Upper Airway Dimensions and Movements in Bronchial Asthma in Bronchial Asthma. The American Review of Respiratory Disease, 133, 1143-1149.

[24] McCarthy, D.S. and Milic-Emili, J. (1973) Closing Volume in Asymptomatic Asthma. The American Review of Respiratory Disease, 107, 559-570. https://doi.org/10.1164/arrd.1973.107.4.559

[25] Shee, C.D., Ploy-Song-Sang and Milic-Emili, J. (1985) Decay of Inspiratory Muscle Pressure during Expiration in Conscious Humans. Journal of Applied Physiology, 58, 1859-1865. https://doi.org/10.1152/jappl.1985.58.6.1859

[26] Mortola, J.P., Magnante, D. and Saetta, M. (1985) Expiratory Pattern of Newborn Mammals. Journal of Applied Physiology, 58, 528-533. https://doi.org/10.1152/jappl.1985.58.2.528

[27] Eissa, N.T., Ranieri, V.M., Corbeil, C., et al. (1991) Analysis of Behavior of the Respiratory System in ARDS Patients: Effects of Flow, Volume, and Time. Journal of Applied Physiology, 70, 2719-2729. https://doi.org/10.1152/jappl.1991.70.6.2719

[28] Guerin, C., Coussa, M.-L., Eissa, N.T., et al. (1993) Lung and Chest Wall Mechanics in Mechanically Ventilated COPD Patients. Journal of Applied Physiology, 74, 157-1580. https://doi.org/10.1152/jappl.1993.74.4.1570

[29] Nadel, J.A. and Tierney, D.F. (1961) Effect of a Previous Deep Inspiration on Airway Resistance in Man. Journal of Applied Physiology, 16, 717-719. https://doi.org/10.1152/jappl.1961.16.4.717

[30] Gump, A., Haughney, L. and Fredberg, J. (2001) Relaxation of Activated Airway Smooth Muscle: Relative Potency of Isoproterenol vs. Tidal Stretch. Journal of Applied Physiology, 90, 2306-2310. https://doi.org/10.1152/jappl.2001.90.6.2306 
[31] Lavoie, T.L., Ramaswamy, K., Siegel, H.R., et al. (2012) Dilatation of the Constricted Human Airway by Tidal Expansion of Lung Parenchyma. American Journal of Respiratory and Critical Care Medicine, 186, 225-232. https://doi.org/10.1164/rccm.201202-03680C

[32] Koulouris, N.G. and Hardavella, G. (2011) Physiological Techniques for Detecting Expiratory Flow Limitation during Tidal Breathing. The European Respiratory Review, 20, 147-155. https://doi.org/10.1183/09059180.00001911

[33] Boczkowski, J., Murciano, D., Pichot, M.-H., et al. (1997) Expiratory Flow Limitation in Stable Asthmatic Patients during Resting Breathing. American Journal of Respiratory and Critical Care Medicine, 156, 752-757. https://doi.org/10.1164/ajrccm.156.3.9609083

[34] Filippelli, M., Pacini, F., Romagnoli, I., et al. (2000) Airway Obstruction and Chronic Exertional Dyspnea in Patients with Persistent Bronchial Asthma. Respiratory Medicine, 94, 694-701. https://doi.org/10.1053/rmed.2000.0803

[35] Melissinos, C.G., Webster, P., Tien, Y.K., et al. (1979) Time Dependence of Maximum Flow as an Index of Nonuniform Emptying. Journal of Applied Physiology, 47, 1043-1050. https://doi.org/10.1152/jappl.1979.47.5.1043

[36] Liistro, G., Veritier, C., Dury, M., et al. (1999) Expiratory Flow Limitation in Awake Sleep-Disordered Breathing Subjects. European Respiratory Journal, 14, 185-190. https://doi.org/10.1034/j.1399-3003.1999.14a31.x

[37] Baydur, A., Wilkinson, L., Mehdian, R., et al. (2004) Extrathoracic Flow Limitation in Obesity and Obstructive and Restrictive Disorders: Effects of Increasing Negative Expiratory Pressure. Chest, 125, 98-105. https://doi.org/10.1378/chest.125.1.98

[38] Ninane, V., Leduc, D., Kafi, S.A., et al. (2001) Detection of Expiratory Flow Limitation by Manual Compression of the Abdominal Wall. American Journal of Respiratory and Critical Care Medicine, 163, 1326-1330. https://doi.org/10.1164/ajrccm.163.6.2004150

[39] Ingram, R.H. and Schilder, D.P. (1966) Effect of Gas Compression on Pulmonary, Flow, and Volume Relationship. Journal of Applied Physiology, 21, 1821-1826. https://doi.org/10.1152/jappl.1966.21.6.1821

[40] Shore, S., Milic-Emili, J. and Martin, J.G. (1982) Reassessment of Body Plethysmographic Technique for the Measurement of Thoracic Gas Volume in Asthmatics. The American Review of Respiratory Disease, 126, 515-520.

[41] Rodenstein, D.O., Stanescu, D.C. and Francis, C. (1982) Demonstration of Failure of Body Plethysmography in Airway Obstruction. Journal of Applied Physiology Respiratory Environmental and Exercise Physiology, 52, 949-954. https://doi.org/10.1152/jappl.1982.52.4.949

[42] Jaeger, M.J. (1982) Effect of the Cheeks and the Compliance of Alveolar Gas on the Measurement of Respiratory Variables. Respiration Physiology, 47, 325-340. https://doi.org/10.1016/0034-5687(82)90061-5 